\title{
Extending Shelf Life of Pasteurized Milk via Chitosan Nanoparticles
}

\author{
Sadeq Muneer Shawkat ${ }^{1 *}$ (D) , Mohammed Al-Jawasim² ${ }^{2}$ and Luay Salam \\ Khaleefah $^{3}$ iD \\ ${ }^{1}$ Department of Dairy Science, College of Food Science, Al-Qasim Green University, 51013, Al-Qasim, Babylon, \\ Iraq. ${ }^{2}$ Department of Environmental Health, College of Environmental Science, Al-Qasim Green University, 51013, \\ Al-Qasim, Babylon, Iraq. ${ }^{3}$ Department of Food Science, College of Food Science, Al-Qasim Green University, 51013, \\ Al-Qasim, Babylon, Iraq.
}

\begin{abstract}
The current study aimed to extend the shelf life of pasteurized milk through addition of chitosan nanoparticles (CNP), which were obtained from chitosan by ionotropic gelation and sonication methods. Physicochemical characteristics of CNP were characterized by fourier transform-infrared spectroscopy (FTIR), zetasizer and transmission electron microscopy (TEM). FTIR spectra analysis of CNP shows a distinctive band at $1150 \mathrm{~cm}^{-1}$ due to stretching vibration of phosphate groups. Size of the freshly prepared CNP ranged from 90 to100 $\mathrm{nm}$ but after two weeks of storage at room temperature the size increased to $120-130 \mathrm{~nm}$. By using TEM, freshly prepared nanoparticles appeared as spherical in shape with a little fragmentation of polymer chain and swelling but still translucent after 2 weeks of storage. Synthesized CNP at a concentration of $0.3 \% \mathrm{w} / \mathrm{v}$ has the ability to inhibit growth of vegetative cells of B.cereus in pasteurized milk stored at $5^{\circ} \mathrm{C}$ and extend the shelf life of pasteurized milk from two weeks to 30 days. The addition of $0.3 \% \mathrm{w} / \mathrm{v}$ CNP had no effects on the physicochemical properties, such as rancidity, $\mathrm{pH}$ and color, of pasteurized milk.
\end{abstract}

Keywords: Chitosan, Nanoparticles, Psychrotrophic Bacteria, Pasteurized milk, Bacillus cereus.

\footnotetext{
*Correspondence: sadeq.muneer@gmail.com; +9647719788206
}

(Received: 23 July 2019; accepted: 17 December 2019)

Citation: Sadeq Muneer Shawkat, Mohammed Al-Jawasim and Luay Salam Khaleefah, Extending Shelf Life of Pasteurized Milk via Chitosan Nanoparticles, J Pure App/ Microbiol., 2019; 13(4):2471-2478. https://doi.org/10.22207/JPAM.13.4.62

(c) The Author(s) 2019. Open Access. This article is distributed under the terms of the Creative Commons Attribution 4.0 International License which permits unrestricted use, sharing, distribution, and reproduction in any medium, provided you give appropriate credit to the original author(s) and the source, provide a link to the Creative Commons license, and indicate if changes were made. 


\section{INTRODUCTION}

Nanotechnology is a promising technology that has proven its significance in various areas such as medicine, agriculture and environment, with a wide range of applications. Nanotechnology involves manipulation of material size scale ranging from 1 to $100 \mathrm{~nm}$. The nanostructured materials have superior properties due to increasing the surface area to volume ratios compared to the same material in bulk ${ }^{1}$. Nanomaterials are synthesized by many techniques, including thermal decomposition, co-precipitation, microemulsion, chemical vapor deposition and laser pyrolysis. However, most these techniques are complicated processes with dilemmas of being inefficient in energy utilization, expensive, toxic, and consequently their potential environmental impact. Therefore, there is a growing demand to implement green and sustainable methods for nanoparticles synthesizing ${ }^{2-4}$.

In current study, we mainly focus on the aspects of functionality and applicability of chitosan in food science by using chitosan nanoparticles as a preservative material. Chitosan is a linear polysaccharide that's commercially produced by deacetylation of chitin ${ }^{5}$. It has been widely used in different applications because of its favorable properties such as solubility, fat binding capacity, water binding capacity, biocompatibility, non-toxicity, biodegrability, selective permeability, reactivity of the deacetylated amino groups and antimicrobial activity. These properties are affected by the method of preparation and origin species $^{6,7}$. Antimicrobial activity of chitosan is related to its positive charge and by interacting with negative charge of bacterial membranes. This electrostatic interaction leading to cell membrane lysis presenting as a reasonable cause of chitosan antimicrobial activity ${ }^{8,9}$. Chitosan also can interact with essential microbial nutrients leading to disruption of microbial growth and eventually death ${ }^{10}$. The physico-chemical properties of chitosan such as increasing its solubility in water, antimicrobial activity and other sensory properties have been improved at the nano-size ${ }^{11}$.

Raw milk is transported in refrigerated tanks at $<7^{\circ} \mathrm{C}$ and contamination may occur due to the growth of psychotropic organism, particularly Pseudomonas spp, Bacillius spp and Clostridium spp. ${ }^{12}$. Milk spoilage could occur at any stage from farm to consumers even when milk is treated by heat (pasteurization technique). The storage of milk in refrigerators encourages the growth of Psychrotrophic bacteria, which are able to grow below $7^{\circ} \mathrm{C}$ and form vegetative cells that resist the pasteurization process. Additionally, pasteurization induces sporulation process of some species like Gram-positive Bacillus cereus ${ }^{13}$. Psychrotrophic bacteria have the ability to form hydrolytic enzymes such as lipase, proteases and phospholipases. These enzymes are resistance to high temperature and cause milk spoilage by changing the physicochemical and sensory properties of milk leading to economic loss. The hydrolysis of casein by proteases enzymes leads to milk coagulation and undesirable changes in liquid milk and dairy products flavor, such as bitterness, metallic taste and rancidity ${ }^{14}$. The objective of the current study was to examine chitosan nanoparticles effects, particularly chitosan effects on extending the shelf life of pasteurized milk.

\section{MATERIALS AND METHODS \\ Preparation of Chitosan Nanoparticles}

Chitosan was purchased from Chemical

Point UG Company (Germany), degree of deacetylation was $\geq 75 \%$, molecular weight 200 $\mathrm{KDa}$. Nanochitosan solution was prepared by ionotropic gelation method by dissolving 100 $\mathrm{mg}$ of chitosan in $1 \% \mathrm{v} / \mathrm{v}$ acetic acid solution; the reaction mixture was stirred at room temperature until the solution became clear. The mixture was adjusted to $\mathrm{pH} 6.5$ by addition of 0.1 molar sodium hydroxide solution. At room temperature, 10 $\mathrm{ml}$ of tripolyphosphate aqueous solution with a concentration of $0.80 \mathrm{mg} / \mathrm{ml}$ was added dropwise under magnetic stirrer at $750 \mathrm{rpm}$ in a Pyrex glass flask. Then, the solution was sonicated at $80 \%$ amplitude for 10 min by SB-5200 DTD Ultrasonic Cleaner, at room temperature ${ }^{15}$. The solution containing chitosan nanoparticles was filtered by nylon syringe $0.22 \mu \mathrm{m}$ mesh and then was freezedried for subsequent analysis.

\section{Characterization of CNP}

The structural feature of the prepared chitosan nanoparticles was studied by fourier transforms infrared spectroscopy (FTIR), 2 mg of the freeze-dried product was added to $100 \mathrm{mg}$ of $\mathrm{KBr}$ powder, the mixture was pressed under 8 bars for $60 \mathrm{sec}$ to form pellet shapes, which 
were placed in FTIR for analysis using wave number range of $600-4000 \mathrm{~cm}^{-1}$ using a Sell FT-IR Spectrometer Model FTIR-600. To study the morphological characteristics of chitosan nanoparticles, transmission electron microscope (TEM) (Jeol JEM-1400, Japan) was used to investigate CNP morphology. A suspension of freeze-dried nanochitosan with distilled water was prepared and sonicated for $3 \mathrm{~min}$. A drop of this suspension was left to dry on a copper grid at room temperature; the sample was stained with tungsten phosphoric acid. CNP size was measured by zetasizer (Malvern Instruments Ltd., UK).

Physico-chemical and sensory properties of milk after addition of CNP

\section{Rancidity, Color measurements and pH}

Rancidity of pasteurized milk after addition of CNP was investigated by measuring the reduction of surface tension by (Sigma 703D Du-Nouy-Ring tensiometer). Color measurement was done by (CM-2600d spectrophotometer, Konica Minolta). pH was measured by using (HI2210-02 Bench Top pH Meter with $\mathrm{pH}$ electrode and ${ }^{\circ} \mathrm{C}$ probe, HANNA). All experiments were done at room temperature in triplicates and best result was taken for different concentrations of CNP (0.0- $0.1-0.2$ and $0.3 \% \mathrm{w} / \mathrm{v})$ during 1,15 and 30 days of storage at $5^{\circ} \mathrm{C}$. Low concentrations of CNP were applied to pasteurized milk, previous study reported that using high concentrations of polysaccharides could interact with milk proteins causing coagulation ${ }^{16}$.

Detection antibacterial activity of CNP by measuring the diameter of inhibition zone on MHA

Thirty samples of raw milk were collected from the Collage of Veterinary's farm, University of Baghdad. Bacillus cereus was isolated and differentiated from other Bacillus spp. by chromogenic agar (CHROMagar, France). $0.2 \mathrm{ml}$ of each samples were inoculated at chromogenic agar and incubated $48 \mathrm{hr}$ at $30^{\circ} \mathrm{C}$. Colonies from sample with highest count of B.cereus were transferred from chromogenic agar into a test tube that contained sterile nutrient broth and incubated for $24 \mathrm{hr}$ at $37^{\circ} \mathrm{C}$. After incubation, $400 \mu \mathrm{L}$ of bacterial suspension of $10^{6} \mathrm{CFU} / \mathrm{ml}$ was transferred by micropipette into Muller-Hinton agar (MHA) and spreading by sterile spreader then petri dish was incubated for $24 \mathrm{hr}$ at $37^{\circ} \mathrm{C}$. Four wells with $6 \mathrm{~mm}$ diameter were punched on MHA by a cork borer. These wells were sealed by adding drops of molten MHA. Fifty $\mu \mathrm{L}$ of CNP solutions with different concentrations (0.1-0.2-0.3\%) w/v were poured into the wells. Petri dishes were kept at $4^{\circ} \mathrm{C}$ for 3 $\mathrm{hr}$ to ensure complete diffusion of CNP. After that, the dishes were incubated at $37^{\circ} \mathrm{C}$ for $24 \mathrm{hr}$. The diameter of the inhibition zone was measured ${ }^{17}$.

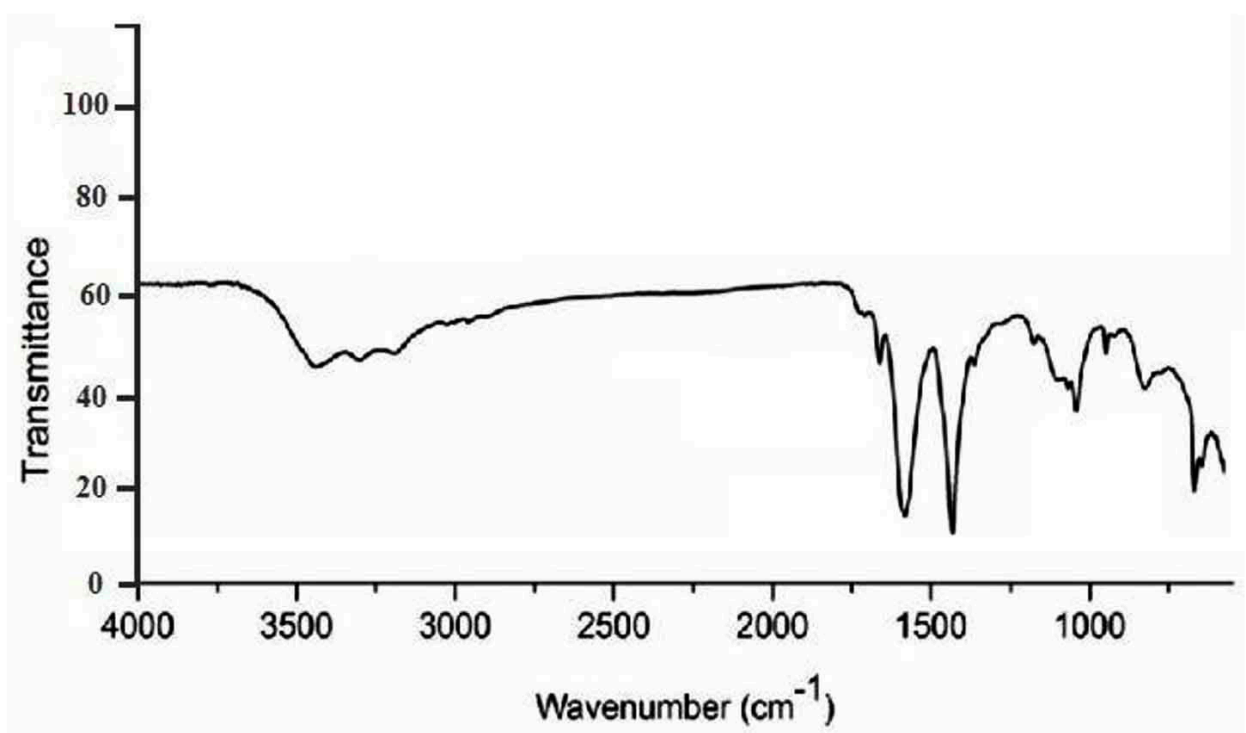

Fig. 1. Characterizations of chitosan nanoparticles (CNP) by sell FT-IR spectrometer 600 . 
Addition of chitosan nanoparticles to raw milk Chitosan nanoparticles were added at different concentrations (0.0-0.1-0.2 - 0.3 $\%) \mathrm{w} / \mathrm{v}$ to $15 \mathrm{ml}$ test tubes containing raw milk sample which was previously diagnosed with highest count of $B$. cereus. The treatments were done in triplicates. After addition of chitosan nanoparticles, the raw milk was pasteurized at $72^{\circ} \mathrm{C}$ for $15 \mathrm{sec}$. Then, these samples were stored at $5^{\circ} \mathrm{C}$ for 30 days. During storage period, the microbiological test (culturing on chromogenic agar) was done to investigate the growth of B.cereus at day 1,15 and 30 of storage.

\section{RESULTS AND DISCUSSION Characterization of CNP}

In fig.1, FTIR spectra of chitosan nanoparticles shows a distinctive band at 3440 $\mathrm{cm}^{-1}$, which was attributed to stretching vibration of $-\mathrm{NH}_{2}$ and $-\mathrm{OH}$ groups that is give an indication

Table 1. The mean of inhibition zones diameter $(\mathrm{mm})$ of three concentrations of chitosan nanoparticles against $B$. cereus.

\begin{tabular}{lc}
\hline $\begin{array}{c}\text { Concentration of } \\
\text { CNP }(\mathrm{w} / \mathrm{v})\end{array}$ & $\begin{array}{c}\text { Zone of inhibition } \\
(\mathrm{mm})\end{array}$ \\
\hline $0.1 \%$ & 6 \\
$0.2 \%$ & 10 \\
$0.3 \%$ & 15 \\
\hline
\end{tabular}

on enhancing hydrogen bonding of molecules. Bands at $1650 \mathrm{~cm}^{-1}, 1590 \mathrm{~cm}^{-1}$ and $1315 \mathrm{~cm}^{-1}$ were caused by the absorption of Amide I $\left(\mathrm{CONH}_{2}\right),-\mathrm{NH}_{2}$ bending and Amide III respectively. $\mathrm{CH}_{2}$ wagging gave an absorption band at $1410 \mathrm{~cm}^{-1}$ another distinctive band at $1150 \mathrm{~cm}^{-1}$ due to $\mathrm{P}=0$ stretching vibration from phosphate groups which was not obtained in FTIR of classic chitosan as previous studies mentioned ${ }^{18-20}$.

TEM micrograph shown in fig. 2 was observed immediately after formulation and upon two weeks of storage at room temperature. The freshly ultrasonicated chitosan nanoparticles showed a spherical shape with a little fragmentation of polymer chain, zetasizer gives average size diameter range of (90nm-100nm). After two weeks of storage, the nanoparticles became larger due to

Table 2. Bacillus cereus count (CFU/mL) of pasteurized milk with chitosan nanoparticals (CNP) at different concentrations $(0.1,0.2$ and $0.3 \% \mathrm{w} / \mathrm{v})$ and without CNP during $(1,15$ and 30$)$ days of storage at $5^{\circ} \mathrm{C}$.

\begin{tabular}{lcccc}
\hline $\begin{array}{l}\text { Storage } \\
\text { period }\end{array}$ & \multicolumn{3}{c}{$\begin{array}{c}\text { B. cereus count (CFU/ml) } \\
\text { Concentration of CNP } \\
\text { (day) sample (\% W/V) }\end{array}$} \\
\cline { 2 - 5 } & $0 \%$ & $0.10 \%$ & $0.20 \%$ & $0.30 \%$ \\
\hline 1 & $1 \times 10^{-1}$ & $1 \times 10^{-1}$ & $1 \times 10^{-1}$ & $1 \times 10^{-1}$ \\
15 & $6 \times 10^{-7}$ & $5 \times 10^{-1}$ & $3 \times 10^{-1}$ & $2 \times 10^{-1}$ \\
30 & $>10^{-8}$ & $3 \times 10^{-1}$ & $2 \times 10^{-1}$ & $<10$ \\
\hline
\end{tabular}

(a)

(b)

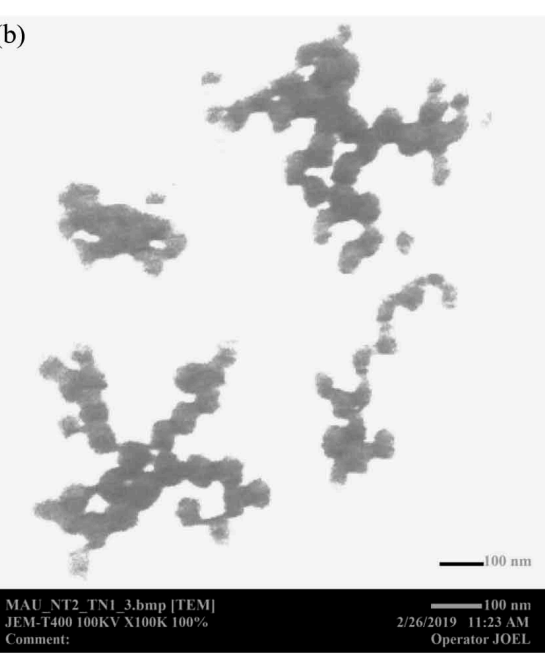

Fig. 2. TEM photographs of chitosan nanoparticles (a) freshly prepared with size diameter range of 90nm -100nm; (b) two weeks of storage with size diameter range of 120nm -130nm. 
swelling by osmosis with an average size of about (120nm-130nm). These swelling nanoparticles fragmented and became as feeble branches. The mixture had a translucent appearance upon storage because the radius of nanoparticles was not increasing to the size which causing turbidity. Detection antibacterial activity of CNP by measuring the diameter of inhibition zone on MHA

Four out of thirty raw milk samples were diagnosed with B.cereus which appeared as blue with white halo colonies on chromogenic agar. Sample with highest count $\left(1 \times 10^{6} \mathrm{CFU} / \mathrm{ml}\right)$ of B.cereus was selected to detect the diameter of inhibition zone by CNP. Table 1 shows the inhibitory activity of chitosan nanoparticles against B.cereus. Results showed that at the concentration $0.1 \%$ $\mathrm{w} / \mathrm{v}$, the diameter of inhibition zone was $6 \mathrm{~mm}$ but when the concentration have been increased to $0.2 \% \mathrm{w} / \mathrm{v}$ inhibition zone diameter was also increased to $10 \mathrm{~mm}$, with a concentration of $0.3 \%$ $\mathrm{w} / \mathrm{v}$ the inhibition zone diameter was increased to $15 \mathrm{~mm}$. These results indicate that the inhibitory activity of CNP against microbes increases as its concentration increases according to previous studies $^{21}$.

\section{Addition of chitosan nanoparticles to raw milk}

Results showed that B.cereus counts of raw milk after pasteurization with and without CNP which stored at $5^{\circ} \mathrm{C}$ (table 2). During the first day of storage, $B$. cereus count for pasteurized milk with different concentrations of CNP (0.1$0.2-0.3 \%) \mathrm{w} / \mathrm{v}$ was comparable as B.cereus count of pasteurized milk without CNP $(1 \times 10 \mathrm{CFU} / \mathrm{ml})$. At

Table 3. Changes in rancidity of pasteurized milk with chitosan nanoparticals (CNP) at different concentrations $(0.1,0.2$ and $0.3 \% \mathrm{w} / \mathrm{v})$ and without CNP during $(1,15$ and 30 ) days of storage at $5^{\circ} \mathrm{C}$.

\begin{tabular}{lcccc}
\hline $\begin{array}{l}\text { Storage } \\
\text { period } \\
\text { (day) }\end{array}$ & \multicolumn{4}{c}{$\begin{array}{c}\text { Concentration of CNP } \\
\text { sample (\% W/V) }\end{array}$} \\
\cline { 2 - 5 } & $0 \%$ & $0.1 \%$ & $0.2 \%$ & $0.3 \%$ \\
\hline 1 & 50.00 & 50.00 & 50.07 & 50.10 \\
15 & 45.00 & 49.02 & 50.04 & 50.50 \\
30 & 40.00 & 49.01 & 50.03 & 50.40 \\
\hline
\end{tabular}

*All surface tension values measurement was given by (dynes $/ \mathrm{cm}^{2}$ ) at room temperature day 15 of storage, the count of Bacillus cereus was increased to $(5 \times 10,3 \times 10$ and $2 \times 10) \mathrm{CFU} / \mathrm{ml}$ for 0.1 , 0.2 and $0.3 \% \mathrm{w} / \mathrm{v}$, respectively. Due to the growth of B.cereus spores but these values did not effect on biological quality of milk as compared with B.cereus count of pasteurized milk without CNP which was $6 \times 10^{7}$ that is indicate heat treatment alone was not enough to kill and prevent the growth of vegetative cells of psychrotrophic bacteria, pasteurized milk without CNP after 15 days of storage was deteriorated by $B$. cereus and became dangerous for human consummation. After 30 days of storage, B. cereus count for pasteurized milk with CNP was $(3 \times 10,2 \times 10$, <10) CFU/ml for the mentioned concentrations respectively as compared with $B$.cereus count of untreated pasteurized milk which was $>10^{8}$ this value effects markedly on biological quality of milk leading to its spoilage and considered high even when compared with acceptable limits of B.cereus in raw milk as mentioned in previous studies ${ }^{22-24}$. The best inhibitory outcome was obtained with $0.3 \%$ of chitosan nanoparticles. The obtained results indicated that the addition of chitosan nanoparticles to milk prevents microbial growth of vegetative cells, enhances microbiological quality, prevents spoilage and increasing its storage life to a maximum 30 days because chitosan is a reusable material and do not loss its antimicrobial activity during storage period according to previous study ${ }^{25}$

Table 4. Changes in color of pasteurized milk with chitosan nanoparticals (CNP) at different concentrations $(0.1,0.2$ and $0.3 \% \mathrm{w} / \mathrm{v})$ and without CNP during $(1,15$ and 30 ) days of storage at $5^{\circ} \mathrm{C}$

\begin{tabular}{|c|c|c|c|c|}
\hline $\begin{array}{l}\text { Storage } \\
\text { period }\end{array}$ & $\begin{array}{l}\text { Concentration of } \\
\text { sample }(\% \mathrm{~W} / \mathrm{V})\end{array}$ & $\mathrm{L}^{*}$ & $a^{*}$ & $b^{*}$ \\
\hline \multirow[t]{4}{*}{$1 \mathrm{~d}$} & 0 & 79.96 & -3.12 & 4.81 \\
\hline & 0.1 & 79.46 & -3.25 & 5.20 \\
\hline & 0.2 & 79.86 & -3.27 & 5.29 \\
\hline & 0.3 & 78.70 & -3.30 & 5.38 \\
\hline \multirow[t]{4}{*}{$15 d$} & 0 & 80.88 & -3.04 & 5.84 \\
\hline & 0.1 & 80.52 & -3.21 & 5.37 \\
\hline & 0.2 & 80.11 & -3.13 & 5.42 \\
\hline & 0.3 & 79.91 & -3.10 & 5.45 \\
\hline \multirow[t]{4}{*}{$30 d$} & 0 & 79.88 & -2.80 & 6.06 \\
\hline & 0.1 & 78.51 & -3.15 & 5.41 \\
\hline & 0.2 & 77.58 & -3.07 & 5.46 \\
\hline & 0.3 & 76.86 & -3.05 & 5.49 \\
\hline
\end{tabular}


as compared with free milk treated by heat alone which has a maximum storage life of two weeks. The inhibitory activity of chitosan nanoparticles increases as its concentration increase.

Physico-chemical and sensory properties of milk after addition of CNP

\section{Rancidity, Color measurements and pH}

The rancidity of milk is measured for two reasons, first to detect the influence of CNP addition to milk on rancidity and to detect the activity of resistant B.cereus, rancidity caused by lipolytic activity which leading to free fatty acids liberation; the resulting free fatty acids reduce pasteurized milk surface tension. Rancidity was measured at room temperature in order to activate the lipolytic enzymes of $B$.cereus ${ }^{26}$. Surface tension values of pasteurized milk without CNP addition were 50.00 dynes $/ \mathrm{cm}^{2}, 45.00$ dynes $/ \mathrm{cm}^{2}$ and 40.00 dynes $/ \mathrm{cm}^{2}$ after day $1,15,30$ of storage respectively. Reduction in surface tension of untreated pasteurized milk was caused by lipolytic enzymes of resistant $B$.cereus leading to rancidity. Surface tension of pasteurized milk with addition of CNP was measured at different concentrations (0.1- $0.2-0.3 \% \mathrm{w} / \mathrm{v})$, the results in table 3 show that, at first day of storage as the concentration of CNP increases the surface tension will also increase but with addition of $0.1 \% \mathrm{w} / \mathrm{v}$ of CNP there was a little reduction in surface tension from 50 to 49.02 and 49.01 dynes $/ \mathrm{cm}^{2}$ at day 15 and 30 of storage respectively because this concentration of CNP was not enough to prevent microbial enzymes activity and growth as compared with $0.3 \% \mathrm{w} / \mathrm{v}$ which gives the best results during all tested days of storage, the results indicate that when concentration of CNP increases the surface tension will also increase due to the prevention of microbial growth and subsequently lipolytic activity ${ }^{27}$ another reason is that CNP has fat binding effect as proved by ${ }^{28}$ that subsequently leading to increase surface tension.

Results in (table 4) showed color measurement of pasteurized milk after addition of CNP, L* values of all samples was not markedly changed during storage period however a concentration of $0.3 \% \mathrm{w} / \mathrm{v}$ had a considerable decreasing effect on $L^{*}$ value at day 30 of storage. $a^{*}$ and $b^{*}$ values of control pasteurized milk samples at day 1 and 30 was increased from -3.12 to -2.80 and from 4.81 to 6.06 , respectively. The color of control samples at day 30 of storage was yellowish as $b^{*}$ values increase to 6.06. From these results chitosan nanoparticles at these tested concentrations did not affect markedly on milk color during its storage period.

The results from fig. 3 showed that pasteurized milk stored at $5{ }^{\circ} \mathrm{C}$ without addition of chitosan nanoparticles, $\mathrm{pH}$ levels were (6.75-6.58) at first and $15^{\text {th }}$ day of storage respectively. At $30^{\text {th }}$ day of storage $\mathrm{pH}$ value was declined to lower than 6.52 which may indicate the growth of microbes. By adding $0.1 \% \mathrm{w} / \mathrm{v}$ of chitosan nanoparticles, $\mathrm{pH}$ values were $(6.72,6.67$ and 6.63$)$ at day 1,15 , 30 of storage respectively. As CNP concentration

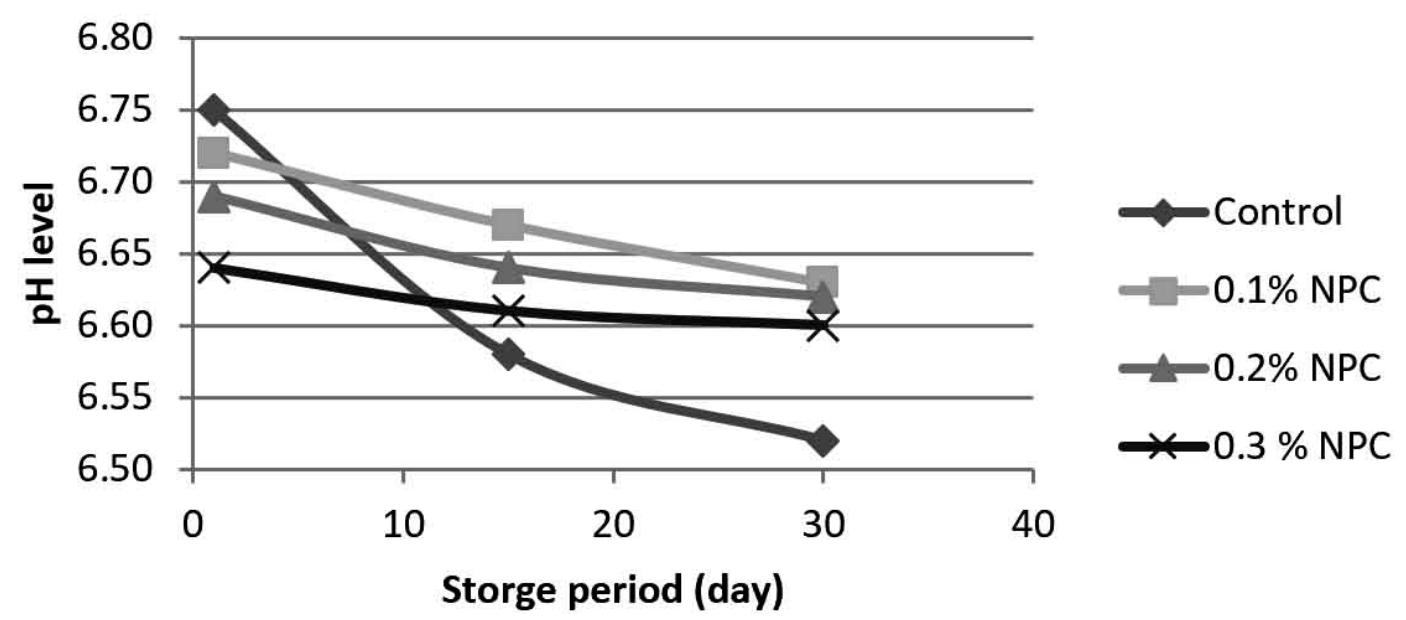

Fig. 3. Changes in $\mathrm{pH}$ of pasteurized milk with chitosan nanoparticals (CNP) at different concentrations $(0.1,0.2$ and $0.3 \% \mathrm{w} / \mathrm{v})$ and without CNP during $(1,15$ and 30$)$ days of storage at $5^{\circ} \mathrm{C}$. 
increased to $0.2 \% \mathrm{w} / \mathrm{v}, \mathrm{pH}$ values were $(6.69,6.64$, and 6.62 ) at day $1,15,30$ of storage respectively. When CNP concentration increased to $0.3 \% \mathrm{w} / \mathrm{v}$ the $\mathrm{pH}$ values were declines to $(6.64,6.61$ and $6.60)$ at day 1,15 and 30 respectively as compared with $\mathrm{pH}$ values of untreated pasteurized milk. These results indicate that the addition of chitosan nanoparticles to pasteurized milk at these tested concentrations leading to a little reduction of $\mathrm{pH}$ values with each increase in CNP concentration but this reduction did not effect on pasteurized milk physical properties and quality because these values still with acceptable limits of pasteurized milk $\mathrm{pH}$ which indicates that the addition of chitosan nanoparticles did not effect on the quality of milk.

\section{CONCLUSION}

In the present study, synthesized chitosan nanoparticles have antibacterial activity by preventing the growth of vegetative cells of $B$. cereus which responsible on milk spoilage after pasteurization. Addition of CNP at $0.3 \% \mathrm{w} / \mathrm{v}$ has no effects on the physicochemical properties of pasteurized milk during its storage period under $5^{\circ} \mathrm{C}$. However, a reduction in $\mathrm{pH}$ occurred and this reduction within expectable limit of pasteurized milk. Addition of CNP is considered as a method for reducing economic losses and health hazards which happen by milk spoilage.

\section{ACKNOWLEDGEMENTS}

The authors would like to thank AlQasim Green University, College of Food Science, Department of Dairy Science, for support and precious assistance the work.

\section{CONFLICTS OF INTEREST}

The authors declare that there is no conflict of interest.

\section{FUNDING}

None.

\section{AUTHOR'S CONTRIBUTION}

All authors listed have made a substantial, direct and intellectual contribution to the work, and approved it for publication.

\section{DATA AVAILABILITY}

All datasets that are generated or analyzed during this study are included in the manuscript and/or in the supplementary files.

\section{ETHICS STATEMENT}

All experimental protocols were approved under the Al-Qasim Green University, College of Food Science, Department of Dairy Science and all experiments were carried out in accordance with approved guidelines.

\section{REFERENCES}

1. Bhushan B. Handbook of nanotechnology. springer, Berlin., 2004. https://doi.org/10.1007/3-540-29838-X

2. Ponce A.A., Klabunde K.J. Chemical and catalytic activity of copper nanoparticles prepared via metal vapor synthesis. J. Mol. Catal. A Chem., 2005; 225: 1-6. https://doi.org/10.1016/j.molcata.2004.08.019

3. Haram S.K., Mahadeshwar A.R., Dixit S.G. Synthesis and characterization of copper sulfide nanoparticles in Triton-X 100 water-in-oil microemulsions. J. Phys. Chem., 1996; 100: 5868-5873. https://doi. org/10.1021/jp952391n

4. No H., K., Meyers S.P. Preparation and characterization of chitin and chitosan -a review. J. Aquat Food Prod. Technol., 1995; 4(2): 27-52. https://doi.org/10.1300/ J030v04n02_03

5. Rout S.K. Physicochemical, functional, and spectroscopic analysis of crawfish chitin and chitosan as affected by process modification. Phd Dissertation, Louisiana State University, Baton Rouge, La., USA, 2001.

6. Inas M. Khaleel Al-aubadi, Dhuha D. Salman. Applications of chitosan in food processing. The Iraqi Journal of Agricultural Sciences, 2009; 40 (3): 136-153.

7. Kango S., Kalia S., Celli A., Njuguna J., Habibi Y. and Kumar R. Surface modification of inorganic nanoparticles for organic in-organic nanocomposites, Prog. Polym Sci., 2013; 38:1232-1261. https://doi. org/10.1016/j.progpolymsci.2013.02.003

8. Rabea E.I., Badawy M.E., Stevens C.V., Smagghe G., Steurbaut W. Chitosan as antimicrobial agent: applications and mode of action. Biomacromolecules., 2003; 4: 1457-1465. https://doi.org/10.1021/ bm034130m

9. Tripathi S., Mehrotra G.K., Dutta P.K. Chitosan based antimicrobial films for food packaging applications. e-Polymers., 2008; 93: 1-7. https://doi.org/10.1515/ epoly.2008.8.1.1082

10. Jia Z., Shen D., Xu W. Synthesis and antibacterial activities of quaternary ammonium salt of chitosan. Carbohydr. Res., 2001; 333: 1-6. https://doi. org/10.1016/S0008-6215(01)00112-4

11. Qi, L., X. Zirong, X. Jiang, C. Hu, and X. Zou. Preparation and antibacterial activity of chitosan nanoparticles. Carbohydr. Res., 2004; 339: 2693-2700. https://doi. org/10.1016/S0008-6215(01)00112-4 
12. Rhea Fernandes. Dairy products Microbiology Handbook: Dairy products ${ }^{1 s t}$ Ed, Royal Society of Chemistry., 2009. https://doi.org/10.1016/S00086215(01)00112-4

13. Wijman J.G.E., de Leeuw P.P.L.A., Moezelaar R., Zwietering M.H., Abee, T. Air-Liquid Interface Biofilms of Bacillus cereus: Formation, Sporulation and Dispersion. Applied and Environmental Microbiology., 2007; 73: 1481-1488. https://doi.org/10.1128/ AEM.01781-06

14. Tchorbanov B., Marinova M., Grozeva L. Debittering of Protein Hydrolysates by Lactobacillus LBL-4 Aminopeptidase. Enzym. Res., 2011; 2011: 1-7. https:// doi.org/10.4061/2011/538676

15. Vaezifar S., Razavi S., Golozar M.A., Karbasi, S., Morshed M., Kamali, M. Effects of some parameters on particle size distribution of Chitosan nanoparticles prepared by ionic gelation method. Journal of Cluster Science, 2013; 24 (3): 891-903. https://doi. org/10.1007/s10876-013-0583-2

16. Ausar S.F., Landa C.A., Bianco I.D., Castagna L.F., Beltramo D.M. Hydrolysis of a chitosan-induced milk aggregate by pepsin, trypsin and pancreatic lipase. Biosci. Biotechnol. Biochem.,2001; 65: 2412-2418. https://doi.org/10.1271/bbb.65.2412

17. Noor Sanbhal, Yan Li, Awais Khatri, Mazhar Peerzada Lu Wang. Chitosan Cross-Linked Bio-based Antimicrobial Polypropylene Meshes for Hernia Repair Loaded with Levofloxacin $\mathrm{HCl}$ via Cold Oxygen Plasma. Coatings, 2019; 9(3): 168; https://doi.org/10.3390/ coatings 9030168

18. Boudouaia N., Bengharez Z., Jellali S. Preparation and characterization of chitosan extracted from shrimp shells waste and chitosan film: application for Eriochrome black T removal from aqueous solutions. Appl. Water Sci., 2019; 9(91): 2-12. https://doi. org/10.1007/s13201-019-0967-z

19. Hameed Abbood Jebur, Aya Ahmed Abdulateef, Zaid Akram Thbit. Chitosan Production from Aspergillus oryzae SU-B2 by submerged fermentation and studying some of its Physiochemical and antibacterial Characteristics. J. Pharm. Sci. \& Res., 2019; 11(2): 609613.

20. Dhanashree B. Gachhi, Basavaraj S. Hungund. Two- phase extraction, characterization, and biological evaluation of chitin and chitosan from Rhizopus oryzae. Journal of Applied Pharmaceutical Science, 2018; 8(11): 116-122. https://doi.org/10.7324/ JAPS.2018.81117

21. Liu N., Chen X., Park H., Liu C., Liu C., Meng X., Yu L. Effect of molecular weight and concentration of chitosan on antimicrobial activity of Escherichia coli. Carbohydrate Polymers, 2006; 64: 60-65. https://doi. org/10.1016/j.carbpol.2005.10.028

22. U.S. Food and Drug Administration, Center for Food Safety and Applied Nutrition Cleaning and sanitizing of containers and equipment, item 12p. In Grade " $\mathrm{A}$ " pasteurized milk ordinance 2003 revision. U.S. Food and Drug Administration, Center for Food Safety and Applied Nutrition, Washington, DC, 2003.

23. Notermans S., Batt C.A. A risk assessment approach for Food-borne Bacillus cereus and its toxins. J. Applied Microbiology, 1998; 84: 51-61. https://doi. org/10.1046/j.1365-2672.1998.0840s151S.x

24. European Union Council Directive 92/46/EEC of 16 June 1992 laying down the health rules for the production and placing on the market of raw milk, heat-treated milk and milk-based products. Official journal of the European Union, 1992; 268: 0001-0031.

25. Andres Y., Giraud L., Gerente C., Le Cloirec P. Antibacterial effects of chitosan powder: Mechanisms of action. Environ. Technol., 2007; 28: 1357-1363. https://doi.org/10.1080/09593332808618893

26. Janstova B., Vorlova L. \& Drackova M. The effect of lipolytic enzymes of Bacillus spp. on quality of ultrahigh-temperature-treated milk. Acta Veterinaria Brno., 2006; 75: 427-435. https://doi.org/10.2754/ avb200675030427

27. Ostanina E. S., Varlamov V. P., \& lakovlev G. I. Inhibition of lipase activityby low-molecular-weight chitosan. Prikladnaia Biokhimiia i Mikrobiologiia, 2008; 44(1): 38-43. https://doi.org/10.1134/S0003683808010055

28. Kim HY, Jeong YT, Bae IH, Kwak HS. Physicochemical and sensory properties of nanopowdered chitosanadded maribo cheese during ripening. Korean J. Food Sci An., 2014; 34: 57-64. https://doi.org/10.5851/ kosfa.2014.34.1.57 